\title{
Efficient identification of critical load model parameters affecting power system voltage stability
}

DOI:

10.1109/PTC.2017.7981204

\section{Document Version}

Accepted author manuscript

Link to publication record in Manchester Research Explorer

\section{Citation for published version (APA):}

Zhu, Y., \& Milanovic, J. V. (2017). Efficient identification of critical load model parameters affecting power system voltage stability. In PowerTech, 2017 IEEE Manchester https://doi.org/10.1109/PTC.2017.7981204

\section{Published in:}

PowerTech, 2017 IEEE Manchester

\section{Citing this paper}

Please note that where the full-text provided on Manchester Research Explorer is the Author Accepted Manuscript or Proof version this may differ from the final Published version. If citing, it is advised that you check and use the publisher's definitive version.

\section{General rights}

Copyright and moral rights for the publications made accessible in the Research Explorer are retained by the authors and/or other copyright owners and it is a condition of accessing publications that users recognise and abide by the legal requirements associated with these rights.

\section{Takedown policy}

If you believe that this document breaches copyright please refer to the University of Manchester's Takedown Procedures [http://man.ac.uk/04Y6Bo] or contact uml.scholarlycommunications@manchester.ac.uk providing relevant details, so we can investigate your claim.

\section{OPEN ACCESS}




\title{
Efficient Identification of Critical Load Model Parameters Affecting Power System Voltage Stability
}

\author{
Yue Zhu, Student Member, IEEE, Jovica V. Milanović, Fellow, IEEE
}

\begin{abstract}
Power system voltage stability is a very important aspect of power system study, and loads have a significant influence on it. With an increasing penetration level of renewable generation, it becomes more crucial. This paper applies Morris screening method to rank the power system load model parameters according to their influence on the voltage stability. The Monte Carlo simulation is used to generate uncertainties to reflect the stochastic behaviour of power systems. The ranking has been made for different loading conditions in order to make the ranking applicable most of the time. Several load models have been applied to investigate the influence of different parameters on voltage stability. The results revealed the important load model parameters and important load buses. The reasons of these parameters being more influential have been analysed.
\end{abstract}

Index Terms-- voltage stability, screening method, load model, load ranking, Monte Carlo

\section{INTRODUCTION}

The power system behavior is becoming more stochastic due to the integration of renewable generation and new types of loads. The power generated by wind turbines and solar panels are always changing. New types of loads like different types of modern non-linear power electronic loads are now representing a large portion of the total load. These uncertainties caused great difficulty to the maintenance of power system stability, including voltage stability. In order to better analyse the power system stochastic behavior, it is necessary to assess the uncertain power system parameters. However, the number of uncertain parameters is proportional to the size of power system. Therefore, for a large power system, it requires a significant amount of time to consider all uncertain parameters. Among these uncertain parameters, some may have significant influence on power system stability, while some other may have influence that can be neglected [1]. Therefore, only the important parameters need to be modelled accurately and the level of accuracy of simulation will not be affected.

In order to identify the most important uncertain parameters, the sensitivity analysis techniques should be applied. For the power system loads, if the most influential loads and corresponding parameters can be identified, then the

The authors are with the School of Electrical and Electronic Engineering, The University of Manchester, PO Box 88, Manchester, M60 1QD, UK (email:yue.zhu@manchester.ac.uk,milanovic@manchester.ac.uk). resources can be devoted to build the accurate load models for these loads only. Ranking power system loads has been studied in many other works considering different types and loads and various types of power system stability [2-6]. Some previous works have applied local sensitivity analysis techniques like singular value decomposition [7-10], while some other recent work requires more computational demanding global methods [11, 12]. Both two kinds of techniques have their drawbacks. However, the screening method, combining the advantages of both local method and global method, is a more efficient way to identify influential parameters [13-15]. The Morris screening method has been applied in many fields such as urban water supply, cancer models, and hydrological modelling to identify the important uncertain parameters.

The voltage stability index is required for determining the impact of load model parameters on voltage stability. The voltage stability index provides a framework of assessing the proximity to voltage collapse. They can be used by power system operators to decide whether the system is in danger of voltage collapse. Among those voltage stability indexes, the Power-Voltage (PV) curve is one of the most reliable ways of identifying the load margin. This method gradually increases the power system load and calculates the power flow for each step until the power flow has no solution [16-18]. The PV curve describes the change of bus voltage caused by the power increase. The critical point is the power system operating conditions that is located at the margin of the voltage stability [19]. The power difference between the voltage collapse point and the initial operating point is the PV margin, which shows the proximity to the voltage collapse.

This paper first applies the Monte Carlo (MC) method to simulate the effects of uncertainties on power voltage stability. The uncertainties in load variation and renewable generation are simulated. The total loading is then increased until the critical point on PV curve is reached. Then the screening method is applied to identify the load model parameters that have large impact on power system voltage stability. The ranking process will run for different loading conditions, and different kinds of load models. This paper is organized as follows: Section II provides a comprehensive overview of Morris screening method. Section III is about how the test system and uncertain parameters are modelled. Section IV are the simulation results of the ranking of load model parameters, and some analysis of the obtained results. And finally Section $\mathrm{V}$ concludes the whole paper. 


\section{ACCEPTED VERSION OF THE PAPER}

\section{MORRIS SCREENING METHOD}

\section{A. Comparison of Different Snesitivity Analysis Techniques}

There are three types of sensitivity analysis techniques: (1) local, (2) screening, and (3) global. The computation time increases from (1) to (3). For the local sensitivity techniques, it investigates how an individual input parameter affect the model output locally. The computation time for this method is short. It only needs $n+1$ model evaluations for an $n$ uncertainties system. However, this technique is not accurate when the system is nonlinear and the uncertainties have significant changes [20, 21]. The screening method can identify the influential uncertain parameters, but cannot provide the information of their contribution to the output. This method requires much less calculation time than the global method, and has much better performance than the local sensitivity analysis techniques [20-22]. In comparison, the global method ranks the uncertain parameters considering all possible input values. It is complex to implement and requires a much longer calculation time [20,21].

After the comparison of these three methods, it can be concluded that if the system is very complicated, like a power system with thousands of buses, it would be very time consuming by using the global method. However, the local method is not reliable enough. Under such circumstances, the screening method is the best choice. The Morris method showed very good performance in the assessment of wastewater treatment, and global warming [23, 24].

\section{B. Overview of Morris Screening Method}

The Morris method can identify important uncertainty variables with a simulation time much shorter than the global method. The uncertain parameters whose changes will cause the largest variation in output will be regarded as the most influential parameter. By using this principle, the Morris method can rank the uncertain parameters and also their impact on the power system voltage stability.

Only one variable is varied at one time by a magnitude of $\Delta$. The elementary effect of the ith factor at a given point $\mathrm{x}$ is

$$
d_{i}(\boldsymbol{x})=\frac{\left[y\left(x_{1}, \ldots, x_{i-1}, x_{i}+\Delta, x_{i+1}, \ldots, x_{k}\right)-y(\boldsymbol{x})\right]}{\Delta}
$$

Where $\mathbf{x}$ is a point in the input region selected such that the perturbed point $\mathbf{x}+\Delta$ is still in input region. $d_{i}$ is the elementary effect. $\Delta$ is the step magnitude. It is a multiple of $1 /(r-1)$, where $r$ is the number of levels.

A trajectory is constructed for each Morris simulation. For each time, only one variable is varied by $\Delta$, and the value of other variables remain the same. Then after that, another variable is selected randomly, and another step of $\Delta$ is made. The whole process finishes when each variable has $r$ steps. Therefore, an input trajectory in the uncertain parameter space is obtained. This is shown as an example in Fig. 1.

The starting point is randomly selected for all uncertain parameters between $\Delta$ and $1-\Delta$. The direction of each step is selected randomly as long as next step does not exceed the input region. The red line in Fig. 1 is one possible trajectory for three uncertain parameters and ten steps.

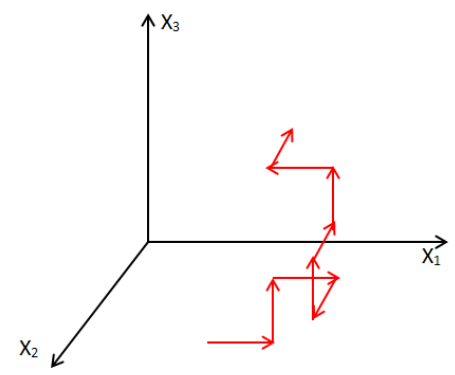

Fig. 1. An example trajectory in the input factor space for $\mathrm{k}=3$ and $\mathrm{r}=10$

There are two indices that can be used to judge the importance of uncertain parameters. One is the mean $\mu$, another is the standard deviation $\sigma$ of the elementary effects for each input variable.

$$
\begin{gathered}
\mu=\frac{1}{r} \sum_{i=1}^{r}\left|d_{i}\right| \\
\sigma=\sqrt{\frac{1}{r} \sum_{i=1}^{r}\left(d_{i}-\mu\right)^{2}}
\end{gathered}
$$

Where $\mu$ represents the sensitivity of the output with respect to ith input variable. If $\mu$ is higher, it means that uncertain parameter is more influential. $\sigma$ represents the standard deviation of the value of the elementary effects. If an uncertain parameter has a large $\sigma$, then it means that its influence on the output is nonlinear, and it has correlation with other variables. One of the major advantages of the Morris method is that compared with global sensitivity technique, it requires much less computation time. For $\mathrm{k}$ parameters and $\mathrm{r}$ levels, it only needs $\mathrm{kr}+1$ simulations.

\section{POWER SYSTEM AND UNCERTAINTY MODELLING}

\section{A. Test Network}

In this paper, the modified version of a reduced order equivalent model of NETS-NYPS test system (New England Test System - New York Power System) was used as the simulation network. The diagram of the system is shown in Fig. 2. The test system has 5 areas, 16 generators, and 68 buses. Among these 68 buses, 26 buses are load buses. The generators G1-G9 belong to NETS, and G10-G13 are generators of NTPS. G14, G15, and G16 represent the other three neighbouring areas. Among these generators, G9 is equipped with a fast-acting static exciter (IEEE STIA) and power system stabilizer (PSS). Other generators use a slow exciter (IEEE DC1A). All generators are equipped with speed governor systems. Generator G1 includes a GAST speed governor. G3 and G9 comprise IEEEG3 (hydro turbine), and G2-G8, G10-G16 contain IEEEG1 (steam turbine). The synchronous generators are modelled by sixth order models. The transmission lines are represented by the standard $\pi$ equivalent circuit. 
There are two types of renewable energy sources (RES) modelled in the test system, which are Type 3 doubly fed induction generators (DFIGs) and Type 4 Full Converter Connected (FCC) units. The wind turbines are represented partly by Type 3 DFIG models and partly by Type 4 FCC models. The photovoltaic (PV) generation, since it is FCC connected, is modelled using Type 4 FCC models as well.

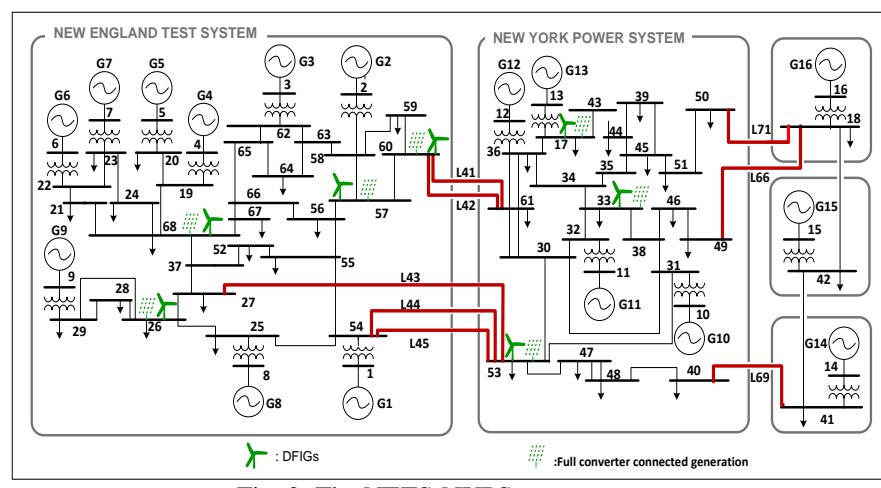

Fig. 2. The NETS-NYPS test system.

\section{B. Modelling Uncertainties}

The uncertainties of load demand, and PV and wind generation are modelled. The load demand follows a normal distribution, with $3 \sigma$ equals to $10 \%$ of $\mu$. The wind generation power output is modelled by a Weibull distribution with a scale parameter of 11.1 and shape parameter of 2.2. The PV power output follows a beta distribution with $a=13.7$ and $\mathrm{b}=1.3$. After considering the uncertainties in demand and RES generation, the power outputs of the synchronous generators are given by the optimal power flow.

\section{Load Models}

In this paper, different load models are applied to investigate the influence of load models and corresponding parameters on voltage stability. The load models chosen are the ones most frequently applied by the industry. They are static exponential load model, and polynomial load model.

The static exponential load model is expressed by (4) and (5) $[25]$ :

$$
\begin{aligned}
& P=P_{n}\left(\frac{U}{U_{n}}\right)^{k_{p u}} \\
& Q=Q_{n}\left(\frac{U}{U_{n}}\right)^{k_{q u}}
\end{aligned}
$$

Where $\mathrm{P}$ and $\mathrm{Q}$ are the real and reactive power drawn by the load at voltage $U . P_{n}$ and $Q_{n}$ are power drawn at the rated voltage $U_{n}$. The parameters $k_{p u}$ and $k_{q u}$ are the parameters that describe the variation of power caused by the variation of voltage. For this paper, these parameters follow the normal distribution. The average values of $P_{n}$ and $Q_{n}$ are equal to one, because the rated power is chosen as the base value. Mean value of $k_{p u}$ is chosen to be 0 , and mean value of $k_{q u}$ is chosen to be 2, as most commonly used in industry [25].

The expressions for the polynomial load model are:

$$
\begin{aligned}
& P=P_{n}\left[p_{1}\left(\frac{U}{U_{n}}\right)^{2}+p_{2}\left(\frac{U}{U_{n}}\right)+p_{3}\right] \\
& Q=Q_{n}\left[q_{1}\left(\frac{U}{U_{n}}\right)^{2}+q_{2}\left(\frac{U}{U_{n}}\right)+q_{3}\right]
\end{aligned}
$$

This model is often referred to as 'ZIP model' because it consists of constant impedance (Z), constant current (I), and constant (P) load components. The parameters $p_{1}$ and $q_{1}, p_{2}$ and $q_{2}$, and $p_{3}$ and $q_{3}$ represent the proportion of constant impedance load, constant current load, and constant power load respectively. The sum of parameters $p_{1}, p_{2}$, and $p_{3}$ and $q_{1}, q_{2}$, and $q_{3}$ is 1 p.u. In this paper, the parameters of $p_{3}$ and $q_{3}$ varies between 0 and 0.7 , the parameters of $p_{2}$ and $q_{2}$ varies between 0 and 0.3 , and $p_{1}$ and $q_{1}$ are calculated from them.

These load models are most frequently used. According to the International survey on load modelling conducted from 2010 to 2011, when doing steady state power system studies, $84 \%$ of utilities and system operators use constant power load model, and $8 \%$ of them use ZIP load model. When doing dynamic power system studies, for active power, $23 \%$ use constant power, $19 \%$ use ZIP, and 23\% apply exponential dynamic load model. for reactive power, $23 \%$ use constant power load model, $22 \%$ use ZIP, $19 \%$ use constant impedance, and 9\% use exponential dynamic load model [25].

\section{RESULTS AND DISCUSSION}

In this study, the Morris screening simulation is carried out in MATLAB R2013a. The PV curve calculation is conducted in DIgSILENT PowerFactory 15.2.

\section{A. Parameters Ranking for Static Exponential Load Model}

The uncertain parameters considered in this stage are exponential parameters $k_{p u}$ and $k_{q u}$ and the power drawn at the rated voltage $P_{n}$ and $Q_{n}$ for the static exponential load model. Each load has two parameters, and there are 26 buses, therefore 52 uncertain parameters in total. The voltage stability index used is the PV margin mentioned earlier.

The level for each uncertain parameter is chosen as 10 , which can have a higher confidence level while still does not require too much computation time. Therefore, $52 \times 10+$ $1=521$ simulations are performed. The results of the parameter ranking are illustrated in Fig. 3 and Fig. 4.

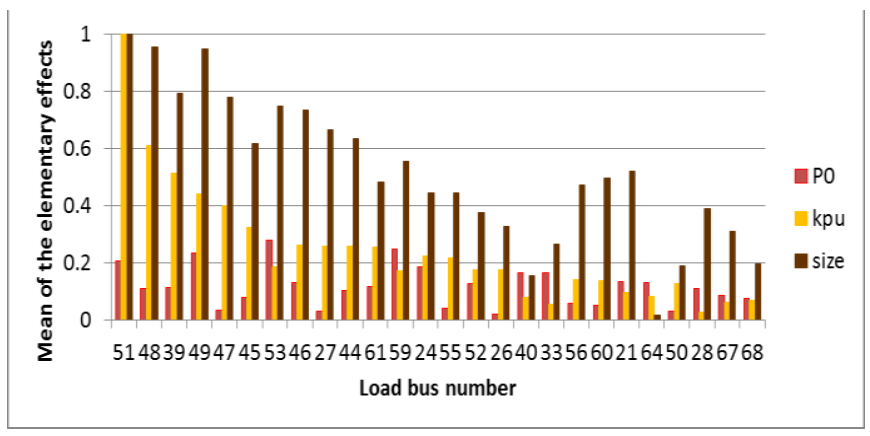

Fig. 3. Ranking of active power parameters of static exponential load model. 


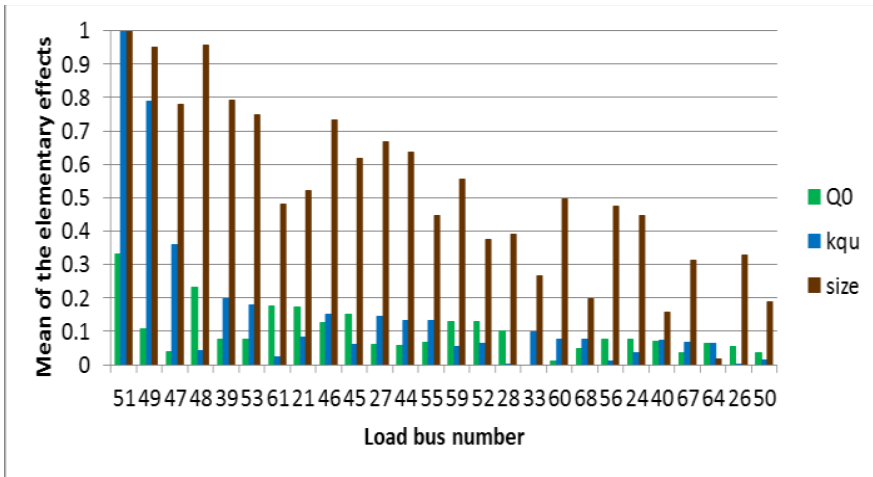

Fig. 4. Ranking of reactive power parameters of static exponential load model.

Then both the active power and reactive power parameters are varied simultaneously, as illustrated in Fig. 5 below. .

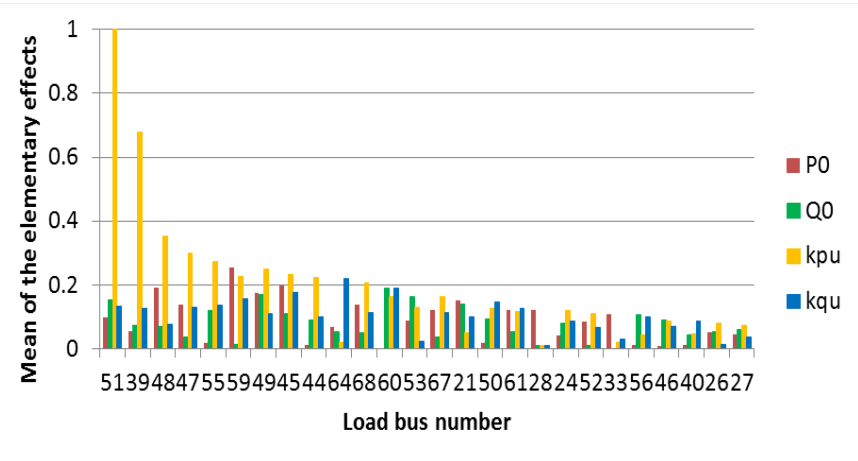

Fig. 5. Ranking of all static exponential load model parameters.

From the figures above, following conclusions can be drawn: 1. Active power parameters are more influential than reactive power parameters. This can be seen from the fact that the ranking of changing all parameters is similar to the ranking of changing only active power parameters. 2. Voltage exponents are more important than the size of the load.

\section{B. Parameter Ranking for ZIP Load Model}

In the case of ZIP load model each load will have active power parameters $\mathrm{Pn}, \mathrm{p} 1, \mathrm{p} 2$, and $\mathrm{p} 3$, and reactive power parameters Qn, q1, q2, and q3, thus 208 parameters in total. The results of the parameter ranking are shown in Fig. 6.

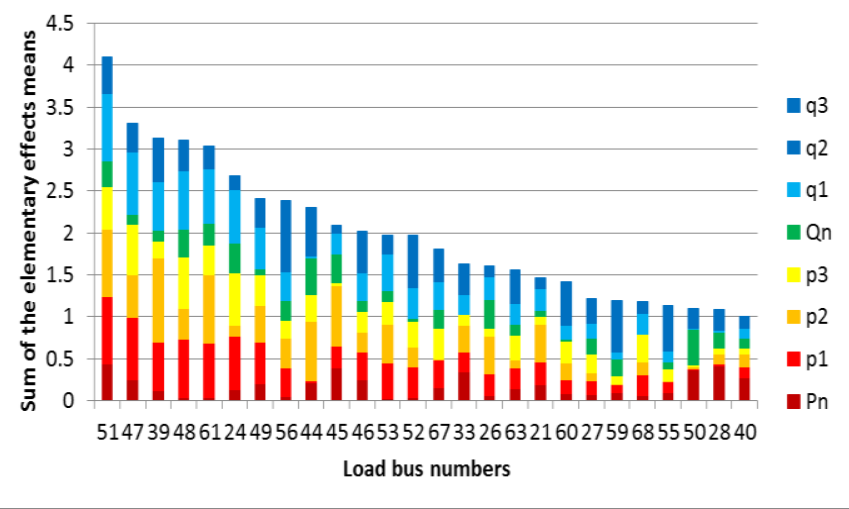

Fig. 6. Ranking of uncertain parameters for ZIP load model.

For Fig. 6, each column represents the sum of all the impact of parameters of each bus. Therefore, unlike in pervious sub-section, where the buses are ranked by the highest column of all its parameters, here buses are ranked by the sum of all columns of its parameters. The contribution of each parameter is distinguished by different colours.

By comparing Fig. 6 with rankings of static exponential load model parameters, it can be concluded that: 1 . The ranking of the most important load buses is the same for both load models and that bus 51 is always the most critical bus regardless of the load model used. 2. For both load models, active power parameters are more influential than reactive power parameters. 3 . The voltage exponents have more impact than the parameters determining load size. The sum of the effects of p1, p2, and p3 is much larger than Pn, which is also the case for q1, q2, q3, and Qn. The cumulative effect of p1, $\mathrm{p} 2$, and $\mathrm{p} 3$ is equivalent to the effect of kpu. Similarly, the cumulative effect of $\mathrm{q} 1, \mathrm{q} 2$, and $\mathrm{q} 3$ is equivalent to that of kqu. The reason of bus 51, 47, 39, and 48 being most important buses is that they are the large loads (bus 51 is the largest load in the system) and far from generators.

\section{Parameter Ranking for Different Loading Conditions}

In order to investigate whether the ranking remains the same for different loadings of the system, the power system loading is changed from the rated loading to maximum loading, average loading, and minimum loading. The loading values are chosen from the annual load duration curve obtained from the real power system data of NETS-NYPS. The Maximum loading correspond to a loading factor of 1.318 , the average loading is 0.495 , and the loading factor of minimum loading is 0.29 . The ranking results are shown in Fig. 7, Fig. 8, and Fig. 9.

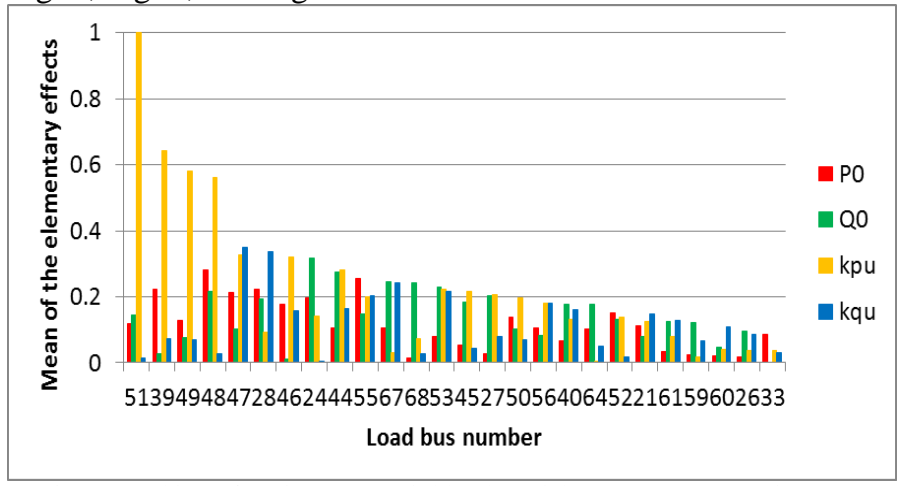

Fig. 7. Ranking of static exponential load model parameters at maximum loading.

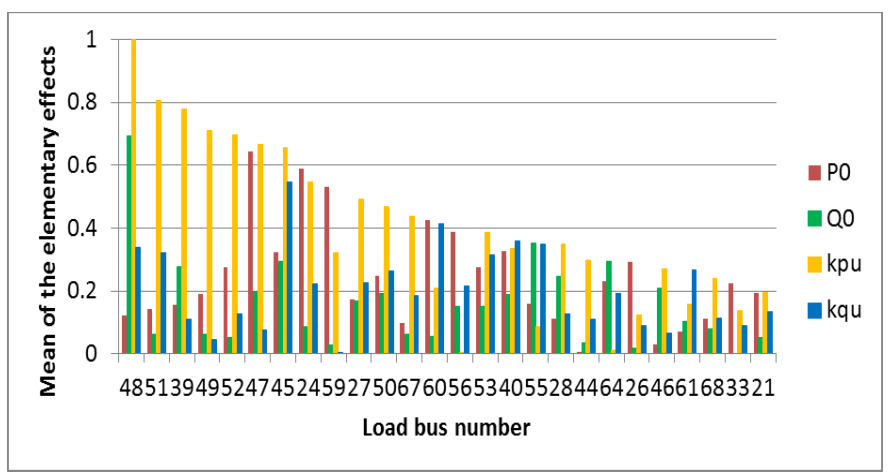

Fig. 8. Ranking of static exponential load model parameters at average loading. 


\section{ACCEPTED VERSION OF THE PAPER}

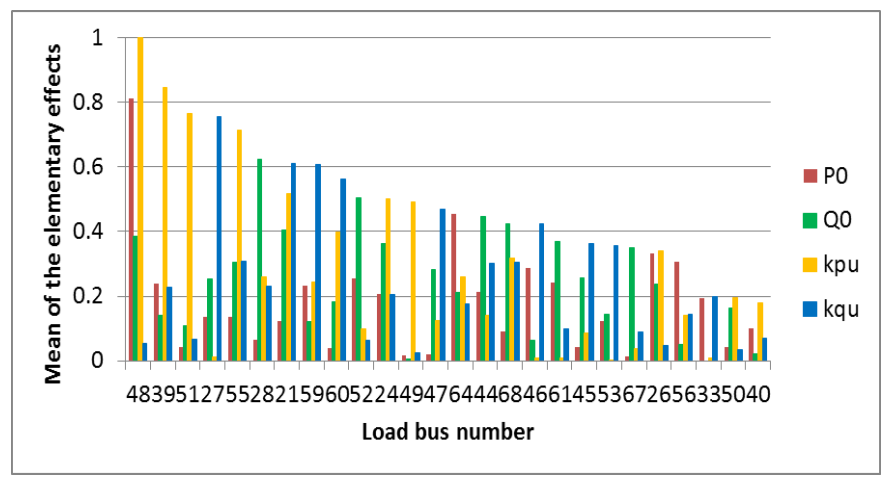

Fig. 9. Ranking of static exponential load model parameters at minimum loading.

From Fig. 7, the ranking for the maximum loading is similar to the ranking obtained at rated loading. However, for lower loading conditions, the variation of ranking order becomes more obvious. For average and minimum loading condition, bus 48 becomes the most critical bus. The effect of bus 47 declines significantly, while some other loads become more important. In all four examined cases the buses 51, 39 and 48 remain among top five most influential loads while buses 49,47 and 55 appear among top five most influential loads in two out of four considered cases. In addition, although kpu remains the most important parameter, the difference between the importance of $\mathrm{kpu}$ and other parameters becomes smaller. Finally it can be also seen that in case of minimum loading condition the importance of reactive power model parameters increases.

\section{CONCLUSIONS}

This paper identifies the most important load model parameters based on their influence on voltage stability, measured in terms of PV margin. The 104 and 208 uncertain load model parameters used for modelling power system loads in the test network considering classical static load model and ZIP load model, respectively, have been ranked. The index used to assess the sensitivity of voltage stability to load model parameters is the PV margin. The parameter variation that has most effect on the PV margin is considered to be the most influential parameter.

After comparison of different sensitivity analysis methods, the Morris screening method was chosen for the analysis as it has much better performance than the local sensitivity analysis method, and is much more computationally efficient than the global sensitivity methods.

The results show the most influential load model parameters and corresponding load buses. The ranking of parameters is not affected much when considering different static load models, i.e. the group of the most important buses remains largely the same, though there is slight difference in the order of importance. The most influential buses, i.e., buses whose load model parameters have the largest effect on voltage stability, are those far from generation centres where large load is connected. The largest loads in the system are connected at buses 51, 48. 49 and 39 and the parameters of these four loads always appear among top five most influential parameters. The active power model parameters tend to be more influential than the reactive power model parameters, and the sensitivity to variation in voltage exponents is higher than the sensitivity to variation in actual load value.

\section{REFERENCES}

[1] A. M. L. da Silva, A. Violin, C. Ferreira, and Z. S. Machado, "Probabilistic evaluation of substation criticality based on static and dynamic system performances," IEEE Transactions on Power Systems, vol. 29, pp. 1410-1418, 2014.

[2] S. Danish, M. Sayed, A. Yona, and T. Senjyu, "Voltage stability assessment index for recognition of proper bus for load shedding," in Information Science, Electronics and Electrical Engineering (ISEEE), 2014 International Conference on, 2014, pp. 636-639.

[3] L. Meiyan, M. Jin, and Z. Dong, "Uncertainty analysis of load models in small signal stability," in Sustainable Power Generation and Supply, 2009. SUPERGEN'09. International Conference on, 2009, pp. 1-6.

[4] D. Han, J. Ma, and R. He, "Uncertainty analysis of load models in dynamic stability," in Power and Energy Society General MeetingConversion and Delivery of Electrical Energy in the 21st Century, 2008 IEEE, 2008, pp. 1-6.

[5] J. V. Milanovic, I. A. Hiskens, and V. A. Maslennikov, "Ranking loads in power systems-comparison of different approaches," Power Systems, IEEE Transactions on, vol. 14, pp. 614-619, 1999.

[6] J.V.Milanovic and I.A.Hiskens, "Effects of load dynamics on power system damping", IEEE Transactions on Power Systems, Vol. 10, No. 2, pp. 1022-1028, 1995

[7] P. A. Lof, T. Smed, G. Andersson, and D. J. Hill, "Fast calculation of a voltage stability index," Power Systems, IEEE Transactions on, vol. 7, pp. 54-64, 1992.

[8] T. Van Cutsem, "Voltage instability: phenomena, countermeasures, and analysis methods," Proceedings of the IEEE, vol. 88, pp. 208-227, 2000.

[9] C. A. Canizares, "On bifurcations, voltage collapse and load modeling," IEEE Transactions on Power Systems, vol. 10, pp. 512-522, 1995.

[10] M. Haque, "On-line monitoring of maximum permissible loading of a power system within voltage stability limits," IEE ProceedingsGeneration, Transmission and Distribution, vol. 150, pp. 107-112, 2003.

[11] T. Homma and A. Saltelli, "Importance measures in global sensitivity analysis of nonlinear models," Reliability Engineering \& System Safety, vol. 52, pp. 1-17, 1996.

[12] Y. L. Levitan, "On the use of variance reducing multipliers in Monte Carlo computations of a global sensitivity index," Computer Physics Communications, vol. 117, pp. 52-61, 1999.

[13] R. D. Braddock and S. Y. Schreider, "Application of the Morris algorithm for sensitivity analysis of the REALM model for the Goulburn irrigation system," Environmental Modeling \& Assessment, vol. 11, pp. 297 $313,2006$.

[14] F. Campolongo, J. Cariboni, and A. Saltelli, "An effective screening design for sensitivity analysis of large models," Environmental modelling \& software, vol. 22, pp. 1509-1518, 2007.

[15] D. King and B. Perera, "Morris method of sensitivity analysis applied to assess the importance of input variables on urban water supply yield-a case study," Journal of hydrology, vol. 477, pp. 17-32, 2013.

[16] F. Capitanescu and T. Van Cutsem, "Preventive control of voltage security margins: a multicontingency sensitivity-based approach," Power Systems, IEEE Transactions on, vol. 17, pp. 358-364, 2002.

[17] H. Nallan and P. Rastgoufard, "Computational voltage stability assessment of large-scale power systems," Electric power systems research, vol. 38, pp. 177-181, 1996.

[18] L. Braz, C. Castro, and C. Murati, "A critical evaluation of step size optimization based load flow methods," Power Systems, IEEE Transactions on, vol. 15, pp. 202-207, 2000.

[19] S. Greene, I. Dobson, and F. L. Alvarado, "Sensitivity of the loading margin to voltage collapse with respect to arbitrary parameters," Power Systems, IEEE Transactions on, vol. 12, pp. 262-272, 1997.

[20] A. Saltelli, K. Chan, and E. M. Scott, Sensitivity analysis vol. 1: Wiley New York, 2000.

[21] X. Song, J. Zhang, C. Zhan, Y. Xuan, M. Ye, and C. Xu, "Global sensitivity analysis in hydrological modeling: Review of concepts, methods, 


\section{ACCEPTED VERSION OF THE PAPER}

theoretical framework, and applications," Journal of hydrology, vol. 523, pp. 739-757, 2015.

[22] B. Iooss and P. Lemaître, "A review on global sensitivity analysis methods," in Uncertainty Management in Simulation-Optimization of Complex Systems, ed: Springer, 2015, pp. 101-122.

[23] M. Ruano, J. Ribes, J. Ferrer, and G. Sin, "Application of the Morris method for screening the influential parameters of fuzzy controllers applied to wastewater treatment plants," Water Science and Technology, vol. 63, pp. 2199-2206, 2011.

[24] B. Bettonvil and J. P. Kleijnen, "Searching for important factors in simulation models with many factors: Sequential bifurcation," European Journal of Operational Research, vol. 96, pp. 180-194, 1997.

[25] W. C4.605, "Modelling and Aggregation of Loads in Flexible Power Networks," CIGRE February 2014. 